\title{
SUPERANDO CONFLITOS NA CONSTRUÇÃO DE UMA PESQUISA \\ COLABORATIVA NA ESCOLA
}

\section{OVERCOMING CONFLICTS IN THE CONSTRUCTION OF A \\ COLLABORATIVE RESEARCH AT SCHOOL}

\author{
Patrícia de Oliveira Rosa-Silva ${ }^{1}$ \\ Álvaro Lorencini Júnior ${ }^{2}$
}

\begin{abstract}
RESUMO
Este estudo enfoca a construção de uma parceria na formação continuada de uma professora de Ciências durante o desenvolvimento de uma pesquisa colaborativa. Analisa episódios de resistências e tensões, assim como ações e reações tanto da pesquisadora como da professora que foram capazes de ajustar e superar tais conflitos para consolidar a pesquisa. O processo de formação continuada envolveu uma estratégia de intervenção reflexiva, denominada autoscopia, simulando uma "sala de espelhos" (SCHÖN, 2000), que levou a professora a refletir sobre a sua prática educativa. Os resultados demonstram que a pesquisa colaborativa, centrada no diálogo e no companheirismo, foi mediadora na solução dos conflitos vivenciados no processo e favoreceu a tomada de decisões na consolidação de estratégias de formação continuada voltadas à professora.
\end{abstract}

Palavras-chave: Formação continuada, pesquisa colaborativa, reflexão sobre a prática.

\begin{abstract}
This study focuses on the construction of a partnership in the continued education of a Science teacher during the development of a collaborative research. It analyzes episodes of resistance and tension, as well as actions and reactions not only on the researcher's but also on the teacher's part, enabling them to adjust themselves and overcome such conflicts in order to consolidate the research. The continued education process involved a reflective intervention strategy, called autoscopy, simulating a "room of mirrors" (SCHÖN, 2000), which led the teacher to reflect on her educational practice. The results demonstrate that the collaborative research, focused on the dialogue and comradeship, mediated the solution of conflicts experienced in the process and favored the decision-making in the consolidation of continued education strategies concerning the teacher.
\end{abstract}

Keywords: Continued education, collaborative research, reflection on practice.

\footnotetext{
${ }^{1}$ Mestranda do Programa de Pós-graduação em Ensino de Ciências e Educação Matemática da Universidade Estadual de Londrina /PR. “Bolsista do CNPq-Brasil”.porsilva@ sercomtel.com.br.

2 Professor Adjunto do Departamento de Biologia Geral da Universidade Estadual de Londrina/PR. alvarojr@uel.br.
} 


\section{INTRODUÇÃO}

Atualmente, a formação continuada do professor na escola é o foco de interesse dos especialistas da área. Diversos pesquisadores (ALARCÃO, 2003; ELLIOT, 1998; ESCUDERO, 1989; IMBERNÓN, 2001; ZEICHNER, 1992) partem da idéia de que a escola é o lugar no qual a prática pedagógica é passível de ser investigada pelos professores e, em conseqüência disso, defendem a importância de ressignificar a formação docente por meio da reflexividade, passando a realidade escolar a ser o centro de referência nesse processo.

No entanto, refletir sobre a prática pedagógica não é tarefa fácil (DEWEY, 1979), nem a formação continuada do professor é algo espontâneo, que se dê pelo simples fato de o profissional estar na escola. É necessário explorar momentos de formação que favoreçamm processos coletivos de intervenção reflexiva da prática pedagógica, capazes de identificar os problemas para resolvê-los, incentivar a sistematização e socialização das práticas docentes, bem como ressituar o trabalho de supervisão/assessoria nesse processo (CANDAU, 1997).

Em vista disso, desenvolvemos a nossa pesquisa na perspectiva colaborativa que, de acordo com Boa Vida e Ponte (2002), constitui uma estratégia na tentativa de solucionar problemas complexos, os quais são difíceis de serem enfrentados pelos professores individualmente. Os mesmos autores afirmam que o reconhecimento da complexidade dos processos educativos, tais como as dificuldades dos alunos em atingir objetivos educacionais, as dificuldades das instituições escolares em desenvolver projetos pedagógicos frutíferos e em estabelecer vínculos com as suas comunidades, justifica a adoção de estratégias de trabalho colaborativo, inclusive para romper com a descrença generalizada da impossibilidade de transformar, de forma positiva, as práticas docentes.

A pesquisa colaborativa entre pesquisador(es) e professor(es) "envolve negociação cuidadosa, tomada conjunta de decisões, comunicação efectiva e aprendizagem mútua num empreendimento que se foca na promoção do diálogo profissional" (DAY, 1999, apud BOA VIDA; PONTE, 2002, p. 46). Trata-se de uma investigação de natureza empírica, marcada pela imprevisibilidade e construída enquanto se desenvolve uma relação interpessoal indispensável.

Com base na concepção de Elliot (1998), que considera o papel do pesquisador como promotor do desenvolvimento do professor em uma perspectiva 
discursiva e reflexiva da sua prática, estabelecemos um relacionamento de parceria com uma professora de Ciências, acompanhando-a nas suas ações pedagógicas, dispondo de quatro horas/atividade ${ }^{3}$ semanais durante o ano letivo de 2006. Inicialmente, o contexto da pesquisa eram as horas/atividade, mas esses momentos foram insuficientes para consolidar a pesquisa. Então, a presença da pesquisadora estendeu-se à sala de aula e também extrapolou os muros da escola.

O processo de consolidação da parceria, na perspectiva de uma pesquisa colaborativa entre a pesquisadora e a professora, baseou-se, fundamentalmente, em assessorar a professora nas suas dificuldades pedagógicas por meio da reflexividade.

Para assessorar com profundidade a professora, foi necessário conhecê-la em situações reais de ensino e aprendizagem na sala de aula. Nesse sentido, propusemos uma estratégia de intervenção reflexiva denominada autoscopia, que permitiu colocar a professora diante de uma "sala de espelhos" para que refletisse sobre a ação, tendo como referência a sua própria prática.

$\mathrm{Na}$ "sala de espelhos", proposta por Donald Schön (2000), há paralelismo entre a prática de formação docente e o ensino prático de sala de aula, em que ocorrem situações homólogas, nas quais os pesquisadores-formadores apóiam-se para auxiliar os professores a problematizarem o seu trabalho pedagógico por meio da demonstração de práticas educativas iguais ou semelhantes às suas. Adotamos a autoscopia como um procedimento similar ao da sala de espelhos, por considerarmos que as reflexões sobre a prática decorreram de situações educativas vivenciadas pela própria professora.

De acordo com Sadalla e Larocca (2004), autoscopia constitui-se na videogravação de uma prática que visa à observação, análise e auto-avaliação pelo protagonista dessa prática. As cenas videogravadas são submetidas a sessões de análise após o desenvolvimento da ação, as quais se destinam à apreensão do processo reflexivo do profissional em foco, por meio de suas falas.

Na parceria colaborativa, a intervenção reflexiva tem a função de estimular a continuidade da formação docente no contexto da sua experiência profissional. Nesse processo podem ocorrer resistências, tensões e conflitos que precisam ser ajustados e

\footnotetext{
${ }^{3}$ A hora/atividade, período em que o professor desempenha funções relacionadas com a docência, que compreende preparação das aulas, processo de avaliação dos alunos, discussões pedagógicas, atendimento à comunidade escolar, atividades de estudo e outras correlatas, será cumprida, integralmente, no mesmo local de exercício e no mesmo turno das horas/aula (Resolução n. 10/2003, Art. 25, § $1^{\circ}$, Secretaria de Estado da Educação do Paraná - SEED/PR).
} 
negociados entre os participantes para que se consolide a parceria, como descrevem Silva e Schnetzler (2000) em um estudo sobre o desenvolvimento de um programa de formação continuada em Ciências com trinta e cinco professores e dois formadores, na modalidade de encontros fora do ambiente escolar. Nesse trabalho, os formadores, ao desenvolverem leitura, análise e discussão de conteúdos específicos em situações pedagógicas semelhantes às dos professores pesquisados, simularam uma "sala de espelhos", por meio da qual solucionaram os conflitos e constataram que os professores puderam reformular as suas próprias ações e concepções de ensino e aprendizagem.

Este estudo, de cunho qualitativo (BOGDAN; BIKLEN, 1994) e colaborativo (BOA VIDA; PONTE, 2002), toma como referência a prática pedagógica de uma professora de Ciências, a partir do contexto escolar, para investigar a seguinte questão: Que ações e reações da pesquisadora e da professora permitiram a superação de resistências e tensões na construção da pesquisa colaborativa, tendo como foco o desenvolvimento da reflexividade docente?

Com este estudo objetivamos responder a essa pergunta por meio de episódios que ocorreram durante o processo de formação continuada de uma professora de Ciências do ensino fundamental, de $5^{\mathrm{a}}$ a $8^{\mathrm{a}}$ série, em uma escola estadual localizada na periferia do município de Londrina/PR. A professora, doravante denominada de Wal, tem licenciatura plena em Biologia, 20 anos de magistério e é efetiva na disciplina de Ciências com 40 horas semanais.

Os dados foram obtidos por meio de relatos anotados em um caderno de pesquisa, pela pesquisadora, e de entrevistas livres gravadas em áudio, por considerarmos que esses procedimentos deixam os envolvidos no processo mais à vontade para expressar as sua idéias.

O presente trabalho está estruturado em duas partes. Na primeira, focamos a construção da parceria, e, na segunda, tecemos considerações acerca do processo desenvolvido. 


\title{
A CONSTRUÇÃO DA PARCERIA
}

Embora os propósitos da parceria entre a pesquisadora e a professora nas horas/atividade demonstrassem a sua perspectiva colaborativa, na prática ocorreram resistências e tensões por parte da professora, que necessitaram ser superadas para que a pesquisa tivesse continuidade, como podemos notar no seguinte relato:

\begin{abstract}
Nos dois primeiros encontros, notei a professora reticente, mas, mesmo assim, confirmamos que eu a acompanharia em quatro horas/atividade semanais, durante um semestre. Já no terceiro contato, fui recebida como uma pessoa inesperada na sala dos professores: de longe, fiquei observando a professora por alguns segundos e percebi que ela mudou o comportamento quando me viu: de espontânea, "fechou-se". Após cumprimentá-la, perguntei o que faria naquela hora/atividade $e$ respondeu-me que elaboraria uma avaliação. Como senti o clima tenso, tomei a iniciativa de não ligar o gravador e de dizer-lhe que precisava conversar a sós na sala de vídeo. Perguntei se eu a estava atrapalhando. A professora de imediato respondeu que não, porém disse-me que o diretor estava com medo da repercussão do projeto porque a escola havia, no ano anterior ao da pesquisa, passado por uma sindicância. Relatou-me que essa preocupação a deixou desmotivada e com receio de participar da pesquisa, porque o projeto visava uma investigação na escola. No final, indagou-me: "O que você quer comigo?" Expliquei, novamente, que o projeto ocorreria em função da sua prática educativa, que as nossas ações também dependiam das suas e não sabíamos, exatamente, quais seriam as análises das suas falas. Na seqüência, a professora demonstrou preocupação em querer superar as minhas expectativas. Aí, comentei de modo explícito: "Por exemplo, quando eu cheguei você me disse que elaboraria uma avaliação para os alunos, então, faremos a avaliação. Não é para você mudar o que você faria por causa da minha presença. Estou aqui para ajudá-la, se quiser. Eu não quero atrapalhá-la nem fiscalizá-la. Quando vim convidá-la para participar do projeto pela primeira vez, você se mostrou preocupada com a sua autoformação e em continuar os seus estudos num mestrado. Podemos unir o útil ao agradável, se quiser!" (Caderno de pesquisa).
\end{abstract}

Esse trecho demonstra uma perspectiva incerta em relação à continuidade da pesquisa. Em vista disso, a nossa reação foi conversar, novamente, com o diretor da escola, que havia concordado com a pesquisa, demonstrando, porém, preocupação quanto à repercussão do projeto no Núcleo Regional da Educação, órgão da Secretaria de Estado da Educação do Paraná (SEED/PR). Lembramos que o trabalho representava uma assessoria à professora de Ciências nas horas/atividade, não havendo, portanto, a intenção de denunciar quaisquer fatos irregulares a ninguém ou de denegrir a imagem da escola de modo algum. Isso foi o suficiente para tranqüilizar o diretor, e ele assentiu que prosseguíssemos com a pesquisa. Vale ressaltar que foi a 
primeira vez que a escola recebeu pesquisadores para investigar a formação docente em serviço.

Quanto à professora, o desafio estava em conquistá-la constantemente. Para isso, passamos a observar mais as suas ações e a nos oferecer para auxiliá-la, por exemplo, em digitações de trabalho, pois Wal não tinha nenhuma habilidade no computador. Também não havia meios de utilizar o da escola, já que os professores não dispunham de nenhum:

Wal me pediu para digitar o Plano Diretor Jovem Participativo - projeto educacional em convênio com a Prefeitura de Londrina - porque estava muito ocupada. Eu me prontifiquei em ajudá-la, pois só seriam duas páginas. Percebo, com isso, que estou me aproximando mais da professora (Caderno de pesquisa).

O propósito da pesquisa que, a princípio, era racional, tendeu a ser afetivo no seguinte sentido: procuramos exercer um papel auxiliador e estimulador das atividades da professora. Desse modo, as nossas ações consistiram em: ajudar Wal na preparação de provas, no uso do mimeógrafo; aceitar os convites da escola para participar de alguns eventos ${ }^{4}$ com a professora e tentar atender às suas dificuldades conforme o seu ritmo, sem perder de vista a nossa função de pesquisador-formador. Também concordamos em não comparecer nas horas/atividade de fim de bimestre, porque Wal preferia preencher, sozinha, notas e outros dados nos seus "livros de chamada".

De sua parte, a professora também sentiu a necessidade de uma interação mais afetiva, conforme o relato a seguir:

Ó Patrícia, eu posso te dizer uma coisa? [...]. Nós não vamos estar juntas seis meses, praticamente? Nós vamos ser assim: "unha e carne", mais ou menos!? Então, se a gente for um pouco cúmplice uma da outra... Porque muitas vezes, tem coisa que com o marido a gente não consegue conversar, assim, tipo: coisas de mulher, que eu falo. Então, eu acho que a gente tinha que ser mais amiga, tipo assim: aquele dia que você entrou lá, segunda-feira, e que eu fiz aquela cara "assim", foi bom você ter falado: "Wal, fala o que está te agoniando, eu não vim aqui te fiscalizar". Foi a melhor coisa. Então, o que eu estou querendo é que a gente seja um

\footnotetext{
${ }^{4}$ Evento $_{1}$ : Palestra sobre "Desperdício Zero" organizada pela Secretaria de Estado do Meio Ambiente/PR, em 14 de março de 2006, com duração de 04 horas. Evento 2 : Curso de extensão promovido pela Universidade Estadual de Londrina/UEL: "Curso de Instrumentação para o Ensino de Biologia" - 20 de maio a 24 de junho de 2006, com duração de 40 horas. O valor da inscrição do curso foi investido pela pesquisadora que o deu de presente de Páscoa à professora, já que Wal havia demonstrado interesse em realizar o curso. Evento 3 : Palestra sobre "Saúde Vocal do Professor" organizada pela Secretaria de Estado da Educação/PR, em 20 de setembro de 2006, com duração de 04 horas.
} 
pouco mais amiga, entendeu? Olha! Eu nunca tive uma parceira no ensino de Ciências, sabia? Eu sempre fiz as coisas trabalhando sozinha, porque eu assumi todas as aulas aqui no Colégio e não tinha com quem repartir. Não é à toa que eu preciso de alguém pra repartir (Professora Wal).

A professora ressalta a importância de termos tido, no início, um diálogo franco para esclarecer os propósitos da pesquisa sobre a prática e, assim, entender que não estava sendo fiscalizada nas suas ações pedagógicas. A partir daí, Wal demonstra certa disposição de estabelecer uma parceria cúmplice e amiga para dividir as suas preocupações do dia-a-dia conosco. Desse modo, a professora tende a ser menos resistente à presença da pesquisadora nas horas/atividade.

Sendo assim, continuamos o processo de parceria centrado na prática da professora com as seguintes ações: identificar expectativas, dificuldades e potencialidades da prática pedagógica para tentar assessorar a professora em uma perspectiva reflexiva e problematizadora da sua prática.

Wal buscava inovar suas aulas, baseando-se em um enfoque sociointeracionista, fundamentado nas interações discursivas em sala de aula. O depoimento a seguir demonstra essa expectativa:

\begin{abstract}
Eu gosto muito que o aluno me questione. Porque oи eu vou aprender com aquela pergunta ou ele vai aprender com a minha resposta. E outra: isso abre o leque pro aluno tímido que não gosta de perguntar. Ele vai ver que a sala toda se mobiliza pra fazer uma questão e no meio do ano ele vai falar, participar. [Eu] vejo que ele se envolve mais. [...]. Eu queria desafio pro aluno responder e ver a importância da matéria dentro do contexto, porque eu vi a professora de Matemática do ano passado trabalhar muito com desafio matemático. E os alunos prestavam atenção e não dispersavam da aula dela de jeito nenhum, nem abriam a boca. E nós, professores de Ciências, precisamos trazer para a sala de aula desafios para os alunos, porque eles estão sendo desafiados no jogo de videogame, na internet... E chegam aqui nesse "blá blá blá blá" de livro... E nada que o ponha em "xeque-mate!" Eu adoro jogo de xadrez. Eu não sei jogar muito bem, mas gosto! Então, eu acho que isso coloca o aluno em "xeque-mate". O aluno está sendo desmotivado, porque nada atrai ele pra escola (Professora Wal).
\end{abstract}

Nesse fragmento, podemos perceber que a necessidade de inovar da professora advém da desmotivação dos alunos, pois o videogame e a internet desafiam mais os estudantes do que a própria aula de Ciências. Além disso, Wal reconhece que a estratégia didática de formulação de perguntas em sala de aula é como um "jogo de xadrez" que possibilita que os alunos se expressem, concentrem-se, envolvam-se e discutam sobre determinado assunto. A professora considera que uma pergunta 
desafiadora aumenta o interesse dos estudantes pelas aulas e, nesse entendimento, ela se espelha na prática pedagógica da professora de Matemática que conseguia a concentração dos alunos, tendo como estratégia um desafio matemático.

Diante dessa necessidade, e partindo da iniciativa da professora, nós a acompanhamos na elaboração do plano de uma aula intitulada "Dia Internacional da Mulher - 08 de março", com duas perguntas norteadoras para os alunos da $5^{\mathrm{a}}$ a $8^{\mathrm{a}}$ série discutirem: "O que é a mulher para você?" e "Qual é a importância da mulher para você?". Sugerimos a Wal que ficasse atenta às falas dos estudantes durante o desenvolvimento das aulas e depois nos relatasse as suas reflexões:

Eu achei que fosse fácil, porque eu achei que era pôr a questão no quadro e eles iriam saber, porque tem aluno que consegue e tem aluno que não consegue chegar no raciocínio da aula. E muitas vezes eles vêm com outra pergunta. [...], e é aí que muitas vezes a gente não está preparada (Professora Wal).

Nesse trecho, podemos notar que a professora demonstra preocupação em direcionar a aprendizagem dos alunos para um conhecimento supostamente correto. Assim sendo, o aluno tem que realizar um determinado raciocínio para ela considerar que ele aprendeu.

Wal sente-se insegura diante da pergunta que fez porque deu margem a outras perguntas, que exigiriam outros desdobramentos. Podemos considerar também que a professora tem pouca habilidade didática para aceitar respostas diferentes, que possam "fugir do seu controle".

$\mathrm{Na}$ perspectiva sociointeracionista, quando se lança mão de perguntas desafiadoras como mediadoras na elaboração do conhecimento escolar, o professor, durante a reflexão na ação, promove as interações discursivas em sala e, assim, a tendência é não haver perguntas sem resposta, nem resposta sem perguntas (LORENCINI JR, 2000).

[...] muitas vezes, ele faz [a questão] pra testar. Ainda mais aluno de 8, que é safado, sem vergonha, ainda mais quem me dirigiu a pergunta, que eu já conheço... Numa aula questionadora já vira uma bagunça total. Eles começam a tirar sarro. Você já fica nervosa e parte pra ignorância. Já corta aquela aula. Pra falar bem a verdade, eu queria que os alunos fossem que nem nós estudamos: pega o livro, decora, pronto e acabou, mas não é assim mais. Eles vêm pra escola motivados pra fazer bagunça, pra fazer outras coisas, pra conversar a aula inteira. Eu quero umas estratégias diferentes pra ver se eles prestam atenção no que eu estou falando. Eu já não sou mais o alvo de atenção deles (Professora Wal). 
Como podemos perceber, Wal sente-se apreensiva diante de algumas perguntas que os alunos fazem, apresentando uma visão nada otimista dos estudantes da $8^{a}$ série. A professora, ao se deparar com uma situação discursiva em que os estudantes "saem do sério", prefere que eles memorizem os conhecimentos a dar continuidade a discussão. Contudo, reconhece que a aula embasada somente no livro não os convence. Podemos inferir também que a docente quer ser reconhecida pelos alunos como uma boa professora; assim, precisa de estratégias que os levem a prestar mais atenção na sua aula.

Em um ensino sociointeracionista, o professor tende a incentivar, a encorajar e a considerar os alunos como parceiros no processo de ensino e aprendizagem (SAINT-ONGE, 2001). Segundo a professora Wal: “o embasamento teórico eu tenho. Parte teórica eu tenho e gosto. O duro é transformar em praticidade pra eles, em pergunta prática".

Por sua fala, podemos reconhecer que a professora apresenta dificuldades em relacionar a teoria com a prática. No ensino reflexivo, o conhecimento teórico dos conteúdos escolares se expressa na ação docente como prática social. Se o professor domina os conteúdos de Biologia, Ciências e seus desdobramentos didáticos, supõe-se que ele saiba teoricamente como se construíram tais conhecimentos; portanto, esperase que ele concilie a teoria com a prática e vice-versa.

Olha, eu preciso entrar numa máquina que refaz. Eu é que tenho que me motivar porque senão... Os alunos estão empolgadíssimos; tudo o que você fala pra eles é bom, maravilhoso [agora, no início de ano]. Mas eu não estou satisfeita com o que eu estou fazendo. Eu sou uma pessoa muito conteudista. Por isso que eu enfrentei esse desafio, porque eu tenho que parar de ser assim. Eu tenho que relaxar! (Professora Wal).

Nesse excerto, podemos notar que Wal tem necessidade de mudar a sua prática seguindo o ritmo dos alunos, mas vê-se limitada ao reconhecer que é conteudista. Ela pretende cumprir a meta estabelecida - utilizar perguntas em sala de aula -, inclusive para melhorar o seu estado de ânimo: "Por isso que eu enfrentei esse desafio, porque eu tenho que parar de ser assim. Eu tenho que relaxar!" A sua expectativa de mudança indica uma potencialidade na sua prática educativa.

A partir dos aspectos identificados, inferimos que a professora passava por dificuldades pedagógicas no desenvolvimento das suas aulas. Tomamos, então, a 
iniciativa de assessorá-la, partindo de reais situações de ensino e aprendizagem em sala de aula para compreender as suas interações com os alunos.

Para tanto, propusemos a leitura e a discussão de quatro referenciais construtivistas $^{5}$ da área de ensino de Ciências, bem como a filmagem das aulas. Essa última estratégia foi necessária para que a professora analisasse o seu próprio trabalho, o que implicaria realizar reflexões sobre a sua prática. Desse modo, procuramos estabelecer uma situação homóloga utilizando a própria aula da professora por meio de um recurso de intervenção reflexiva, denominado autoscopia.

Wal concordou em gravar as aulas em vídeo de acordo com as séries/turmas selecionadas por ela $\left(7^{\mathrm{a}} \mathrm{B}\right.$ e $\left.5^{\mathrm{a}} \mathrm{C}\right)$ e na ocasião em que se sentisse preparada didaticamente para ministrá-las: "Eu não planejo. O meu planejamento do ano passado é o mesmo do ano anterior". E também estava "com medo de fazer alguma besteira em sala".

Assim sendo, optamos pela autoscopia trifásica. $\mathrm{Na}$ primeira fase, audiogravada, ocorreu leitura de textos e preparação dos planos de aula. Na segunda fase, que foi gravada em vídeo, a professora desenvolveu a aula com seus alunos. $\mathrm{Na}$ terceira, houve sessão de discussão de determinadas cenas com o auxílio do vídeo e de um roteiro norteador de questões instigadoras do processo reflexivo sobre a ação. No desenvolvimento da pesquisa foram realizadas oito autoscopias, e durante as nossas discussões surgiram algumas tensões:

\begin{abstract}
Após a primeira videogravação da aula, Wal estava muito ansiosa para se ver na tela da tevê. Sendo assim, ela assistiu à sua aula, espontaneamente, nos últimos instantes da hora/atividade daquele dia, por volta de sete minutos. Quatro dias após, na data da sessão de discussão, Wal teve um comportamento inesperado quando perguntei que evidências ela tinha de que o aluno estava aprendendo naquela aula. Ela respondeu-me emocionada: "É! Então, é isso que eu nunca parei pra ver, nunca parei pra analisar. Eu fiz 20 anos errado? Faz 20 anos que eu estou toda errada". A reação de Wal também me comoveu, mas mantive a calma dizendo-lhe que "20 anos são 20 anos de experiência, de vivência!"
\end{abstract}

\footnotetext{
${ }^{5}$ LORENCINI JÚNIOR, Á. O professor e as perguntas na construção do discurso em sala de aula. 2000. Tese (Doutorado em Educação). Universidade de São Paulo, São Paulo. Capítulos quatro, cinco e seis.

MOREIRA, M. A. Aprendizagem significativa. Brasília: Editora Universidade de Brasília. 1999c. p. $35-48$.

VALLE FILHO, M. R. O professor como produtor do conhecimento. In: CARVALHO, A. M. P. (Coord.). A formação do professor e a prática de ensino. São Paulo: Pioneira, 1988, p. 61-65.

ZABALA, A. A prática educativa: como ensinar. Porto Alegre: ArtMed, 1998. Capítulo três.
} 
Lembrei que ela fizera uma monografia sobre "Clube de Ciências", mas disse-me tristemente: "O Clube de Ciências foi uma fase jovem, se você soubesse que eu já perdi a minha paciência”. No final da sessão, contoume que estava com dor de cabeça. Dois dias depois, liguei-lhe e perguntei se a dor de cabeça tinha sido por causa da análise da fita. Wal respondeu-me que tinha umas limitações de saúde e acrescentou: "se ninguém me desestruturar, como é que eu vou mudar!" (Caderno de pesquisa).

Embora Wal tivesse ciência de que a autoscopia seria mediada por perguntas, e teria como principal objetivo levá-la a refletir sobre a sua prática, concordamos que assistisse à aula no mesmo dia em que foi filmada e, a partir da sessão de discussão propriamente dita, interviemos com perguntas excitadoras do processo reflexivo sobre a ação, tais como "O que está acontecendo naquela cena? Por que você agiu assim? Quais foram as ações/reações dos alunos? No que você estava pensando enquanto você estava fazendo...? Que dificuldades você sentiu no processo de ensino? Quais foram as dificuldades dos alunos?"

Sabíamos do tempo de carreira da professora, e isso despertou a atenção naquele momento, pois, até então, não o tínhamos considerado como um dado relevante no processo de formação docente. Assim, passamos a considerar o significado da formação continuada de uma professora com 20 anos de magistério como um processo meticuloso, uma vez que a intervenção reflexiva causou-lhe desconforto ao reconhecer que nunca havia analisado como os alunos aprendem. Segundo a literatura, as pessoas comportam-se de modo muito particular no processo autoscópico (SADALLA, 2000).

Por outro lado, a fala de Wal, "se ninguém me desestruturar, como é que eu vou mudar!", revela a necessidade de uma intervenção que faça o profissional sentirse realmente insatisfeito, o que pode implicar possíveis mudanças no seu trabalho.

Nas primeiras autoscopias, a professora ficava reticente durante as reflexões sobre a sua prática, esperando que indicássemos o "caminho certo" para desenvolver as aulas e, dessa forma, evitar "supostos erros":

A professora quer a receita pronta para as suas aulas: "Eu queria um negócio que eu chegasse lá, aplicasse e desse certo!” Ela também quer a confirmação das suas respostas como certa ou errada: "Você também não fala se está certo ou se está errado né, Patrícia? Eu vou ficar brava agora!" Por outro lado, ela tem a preocupação de saber se as respostas que me dá têm sentido: "Eu estou falando abobrinha?". As minhas reações nesses instantes eram: "Nem eu sei o que é o certo. Eu estou querendo entender você! O meu papel não é ver se a prática está "certa" ou "errada”, é de ativar o seu pensamento" (Caderno de pesquisa). 
Diante desses conflitos a nossa responsabilidade aumentava cada vez mais. Nesse contexto, tomamos a iniciativa de nos aproximar mais da professora, freqüentando a sua residência para estabelecer um relacionamento mais estreito, a fim de irmos, aos poucos, conquistando a sua confiança e, assim, aliviando as tensões:

\begin{abstract}
Nesta quarta-feira, (03/05/06), tivemos 70 minutos de diálogo. No final, dei à professora o comprovante de inscrição do curso de "Instrumentação para o Ensino de Biologia/UEL". Isso evitou que tivesse de se deslocar da sua casa à Universidade. Wal pediu que eu a acompanhasse até o final do ano, porque precisava de mais tempo de estudo para desenvolver uma aula com perguntas. Imediatamente respondi que sim. Agradeceu-me. Percebi que ela ficou motivada. Quando bateu o sinal da saída, ofereci uma carona a ela e ao professor de Arte, seu marido, até a sua residência, que fica a dois quarteirões da escola. Convidou-me para entrar em sua casa. Então, conheci seus dois filhos e conversamos um pouco sobre família. Como moramos em bairros próximos, combinamos de eu lhe dar carona, aos sábados, para fazermos o curso na UEL. Fomos estreitando os nossos laços de amizade durante os nossos encontros, que se tornaram descontraídos (Caderno de pesquisa).
\end{abstract}

Durante as nossas conversas, Wal comentava que se sentia mais à vontade estudando em casa do que nas horas/atividade na escola. Combinamos encontros em sua residência para realizarmos leitura dos Parâmetros Curriculares Nacionais de Ciências (2001, p. 7-21), referencial de sua preferência. Nessa interação, Wal, espontânea e abertamente, refletia sobre os nossos encontros:

Você se lembra do primeiro dia que você chegou na escola? Não o primeiro dia pra combinar as coisas. Foi um dia que você chegou 7:30, numa segunda-feira, bem no início do ano, [mês de março], que eu fiz. assim... Sabe quando você faz aquela "expressão"! E você falou: "Wal, eu não quero te atrapalhar! Você não precisa ficar constrangida...” E eu falei assim: "Patrícia, não é nada disso!" É que naquele momento eu não estava preparada pra te receber, sabia? Eu estava meio perdidona no que eu ia fazer, no que eu ia falar pros alunos, no que nós íamos... Aí eu falei: "agora [que a Patrícia chegou], danou-se tudo!" Então, isso foi um conflito que passou dentro de mim, que depois com o diálogo nós fomos nos acertando. Foi tipo assim: "um chute no escuro", porque a gente não sabe o que está por trás [da pesquisa]. E outra, esse seu empenho em que eu faça as coisas, é pra [eu] ver um outro mundo que existe por aí. Ó, você foi assim, algo, que no final do ano passado [2005], quando você apareceu lá na escola, eu falei assim: "Ai meu Deus do céu! Onde que eu fui amarrar o meu burro!" Eu achava assim: ai, será...? O diretor tinha medo também! [Ele não tem mais] por causa da sua postura, por causa das suas colocações... E outra: do nosso trabalho ser sério (Professora Wal). 
Nesse trecho, Wal torna a falar da resistência e da desconfiança do início da pesquisa e, desse modo, complementa-as com motivos esclarecedores. O primeiro demonstra o seu arrependimento em nos ter aceitado ao seu lado na escola: "Ai meu Deus do céu! Onde que eu fui amarrar o meu burro!". Ela não estava preparada para interagir conosco, por meio do diálogo e da reflexão sobre a sua prática educativa nas horas/atividade: "É que naquele momento eu não estava preparada pra te receber, sabia?" O segundo refere-se ao receio do diretor, que influenciou na sua decisão, deixando-a insegura e, conseqüentemente, reticente nas suas interações conosco.

Uma outra reflexão diz respeito ao primeiro dia da sessão de análise da fita:

[Teve um] dia que eu tive um "piripaque" lá dentro da sala de vídeo. A primeira filmagem, que eи me senti mal, lembra? [...]. Falei assim: "a Patrícia está querendo investigar como é que eu dou aula e tatatá”. Eu pensei até em falar pra você: "eu não quero mais saber disso!" Eu tive assim: um choque do que eu estava vendo, das conversas [dos alunos], das coisas como estavam se organizando. Eu imaginava que você estava querendo que eu mudasse de uma vez a minha aula, que você estava me testando na tese com uma aula de construtivismo mesmo. E eu sou uma pessoa demorada. [...] eu achei que você queria já impor como deveria ser. Eu achei completamente diferente do que está sendo. Eu não conseguia observar que você está tentando me observar do jeito que eu sou mesmo. E você está querendo investigar quais são, realmente, as dificuldades que um professor de Ciências enfrenta dentro da sala querendo mudar a postura. [...] você quer relatar essa angústia do que acontece realmente num professor que tem a tendência de mudar, depois de uma prática longa de não sei quantos anos aí carregando o mundo nas costas, agora resolveu largar. Eu [me] assustei com a pergunta [Que evidências você tem de que o aluno está aprendendo naquela aula?], porque eu pensei: "ela está investigando a minha ação". Passou um "mar de névoa" na minha cabeça, mas agora eu estou vendo que não é isso. $O$ que você está tentando fazer é assim: me colocar na frente, eu mesma. Então, eu estou fazendo uma reflexão da minha ação. Mas não é nada imposto por você, porque você está tentando, junto com essa reflexão, [ver] quais são as angústias que o professor enfrenta numa sala de aula sozinho, sem postura, sem ajuda pedagógica, sem material numa escola pública com " $n$ " problemas de aprendizado, com " $n$ " problemas de aluno. Aluno que tem pai e mãe em casa bonitinho, aluno "do lar" e de tudo quanto é lado. Uma escola assistencialista, uma escola heterogênea em todos os sentidos, não só dentro da sala de aula, porque nós temos professor altamente conservador e nós temos professor altamente modernizado já. E outra, Patrícia, eu não vou deixar isso apagar. Tudo bem: eu não sei se eu consigo processar isso agora [na prática], mas daqui pra frente eu só vou tender a modificar mesmo. Assim, é claro, é devagar, porque é uma coisa... Gente, que eu tenho que ter domínio (Professora Wal).

Esse longo depoimento dado em sua casa evidencia o conteúdo do pensamento da professora na primeira sessão de discussão com o auxílio do vídeo. No início, a docente pensava que interviríamos na sua prática pedagógica de forma 
impositiva, autocrática, ditando regras e mudanças imediatas: "Eu imaginava que você estava querendo que eu mudasse de uma vez a minha aula, que você estava me testando na tese com uma aula de construtivismo mesmo. E eu sou uma pessoa demorada".

Somente com a nossa interação ela foi percebendo o sentido da intervenção reflexiva, na prática: "Eu não conseguia observar que você está tentando me observar do jeito que eu sou mesmo. E você está querendo investigar quais são, realmente, as dificuldades que um professor de Ciências enfrenta dentro da sala querendo mudar a postura".

O nosso propósito foi levar a professora a voltar-se para a sua ação, de modo a refletir sobre si mesma, semelhante a alguém que se observa no espelho: "O que você está tentando fazer é assim: me colocar na frente, eu mesma. Então, eu estou fazendo uma reflexão da minha ação. Mas não é nada imposto por você."

$\mathrm{O}$ vídeo tem a função de um espelho em que a pessoa se contempla, porém sem se olhar nos olhos (FERRÉS, 1996). Na tela da televisão, a professora pôde mirar-se a partir de várias cenas, ou seja, de vários espelhos como em uma "sala de espelhos", alternando as reflexões sobre as ações vividas, observadas e idealizadas (ALARCÃO, 2000).

Nos momentos de autoscopia, pretendíamos que Wal refletisse sobre o seu trabalho para a busca de soluções dos problemas advindos da prática e ir, aos poucos, desenvolvendo as habilidades que se sentisse apta a realizar nas interações discursivas com os alunos. Sendo assim, evitávamos comentar sobre as inadequações das suas aulas, pois se fizéssemos determinados comentários poderíamos inibi-la de externar as suas reflexões, e a tensão seria maior. O excerto a seguir corrobora essa idéia:

Eu achava que você ia investigar assim: "Essa mulher está errada, ou está certa. Ou é assim que faz!" Eu achei que você ia tomar posição, não fazer esse outro tipo de coisa: pôr a minha cabeça pra pensar, pra refletir $e$ eu ver que... Eu ver as coisas! Eu pensei que era completamente diferente. Você me perdoa, né? (Professora Wal).

Neste fragmento, podemos notar como a professora passou a reconhecer a pesquisa:

[...] tudo isso que está acontecendo, essa ação, essa transformação partiu de mim. [...] Eu pensei que você seria uma estagiária comum, que ia observar as minhas aulas, depois ia participar e pronto. Eu não achei que a ação seria voltada pra mim, professora. Por que não usar isso? [...]. 
Então eu não posso mais sentar na cadeira e ficar acomodada. E hoje eu já cheguei mais no aluno, já pedi pra eles... Eu dei uma atividade ainda tradicionalmente, mas eu cheguei mais, eu observei mais, [...] (Professora Wal).

A professora parte da idéia de que exerceríamos uma função como a dos estagiários dos cursos de licenciatura. Isso parece pertinente porque a auxiliamos em tarefas que alunos em formação inicial realizam, tais como a preparação de provas e atividades, no uso do mimeógrafo, e observação das suas ações nas horas/atividade e em sala de aula. Contudo, essa participação seria insuficiente para ajudar Wal nas suas dificuldades. Organizamos, então, uma estratégia de intervenção que estimulou a professora a refletir sobre a ação para tentar solucionar as suas dificuldades, pois "o processo de compreensão e melhoria de seu trabalho deve começar pela reflexão de sua própria experiência” (ZEICHNER; DINIZ-PEREIRA, 2005, p. 66).

No final da sua fala, Wal reflete sobre sua conduta e sobre como começou a mudá-la na prática: levantar da sua cadeira em sala de aula para aproximar-se mais dos alunos e observá-los. Esse é um dos pontos-chave para começar a desenvolver uma aula sociointeracionista: o professor deve deixar a sua passividade em direção ao ensino ativo e reflexivo.

\section{ALGUMAS CONSIDERAÇÕES}

A realização deste estudo na perspectiva de uma pesquisa colaborativa entre a pesquisadora e a professora implicou ações e reações consideradas fundamentais para a superação das resistências, tensões e conflitos originados durante o processo.

A conversa de esclarecimento dos propósitos da pesquisa tranqüilizou o diretor em relação à repercussão do projeto na sua esfera administrativa, e ele assentiu que prosseguíssemos com o trabalho. O diálogo face-a-face com a professora foi uma constante para que ela compreendesse a pesquisa, na prática. Associada ao diálogo, a pesquisa colaborativa permitiu que participássemos dos eventos ocorridos fora da escola com a professora e a auxiliássemos nas atividades pedagógicas. Isso diminuiu a sua resistência.

Contudo, a primeira autoscopia como "sala de espelhos" originou tensões e conflitos, porque a professora considerava que investigaríamos as suas aulas, analisando-as com juízos de valor tais como "certo ou errado", e que iríamos 
“impor” encaminhamentos metodológicos para que desenvolvesse as aulas em uma perspectiva discursiva. Diante dessa dificuldade, tomamos a iniciativa de nos aproximar mais da professora, freqüentando a sua residência, o que ajudou a apaziguar as tensões, pois estávamos em um espaço sem as formalidades do contexto escolar, portanto aconchegante e acolhedor para compartilhar as idéias e as diferenças.

A autoscopia, como estratégia de intervenção reflexiva, foi um recurso de situação homóloga baseada na prática educativa da professora, que lhe possibilitou mirar o universo da sala de aula e refletir sobre a prática para reconsiderar algumas de suas condutas.

Neste trabalho, a situação homóloga que simulou a "sala de espelhos" foi diferente daquela utilizada no estudo de Silva e Schnetzler (2000). Os resultados aqui apresentados contrapõem-se aos das autoras, porque naquela pesquisa ficou demonstrado que a "sala de espelhos" foi mediadora na solução de resistências e conflitos no desenvolvimento do processo de formação continuada dos professores de Ciências, enquanto, neste estudo, a "sala de espelhos" originou tensões, porque esteve apoiada na própria prática da professora. O companheirismo extra-escolar da pesquisadora, no entanto, aliviou as tensões, colaborando para que a professora compreendesse os reais objetivos da pesquisa, ou seja, uma parceria colaborativa pautada na assessoria dos planos de aula e, depois de desenvolvidos em aula, na discussão das ações pedagógicas com o auxílio do vídeo, a fim de aprofundar as reflexões na busca de possíveis mudanças na sua prática.

Mesmo admitindo a escola como centro de formação continuada de professores, este estudo demonstrou que os contextos externos reforçaram a parceria para consolidar a pesquisa sobre a prática pedagógica na escola. Os diversos contatos ajudaram a estreitar o relacionamento interpessoal e a compreender os reais motivos das resistências e conflitos da professora. Logo, podemos considerar que o desenvolvimento da pesquisa colaborativa dependeu, interna e externamente, do contexto do trabalho da professora para estimular o seu processo de formação continuada.

Podemos considerar, ainda, que a pesquisa colaborativa, centrada no diálogo e no companheirismo, foi mediadora na solução dos episódios conflitantes vivenciados e favoreceu a tomada de decisões na consolidação de estratégias de formação continuada voltadas à professora. 
É uma metodologia que, embora tenha a desvantagem da imprevisibilidade dos fatos que ocorrem na escola, favorece a persistência do pesquisador em campo, devido à sua flexibilidade em relação ao tempo, ao espaço e às ações de pesquisa, gerando amadurecimento no processo de aprendizagem, porque possibilita que os colaboradores reflitam sobre as suas relações interpessoais para melhorá-las.

\section{Referências}

ALARCÃO, I. Reflexão crítica sobre o pensamento de D. Schön e os programas de formação de professores. In: Formação reflexiva de professores: estratégias de supervisão. Porto: Porto Editora, 2000. p. 9-39.

. Professores reflexivos em uma escola reflexiva. São Paulo: Cortez, 2003.

BOAVIDA, A. M.; PONTE, J. P. Investigação colaborativa: potencialidades e problemas. In: GTI (Org). Reflectir e investigar sobre a prática profissional. Lisboa: APM, 2002. p. 43-55.

BOGDAN, R. C; BIKLEN, S. K. Investigação qualitativa em educação. Porto: Porto Editora, 1994. p. 47-51.

CANDAU, V. M. Formação continuada de professores: tendências atuais. In: (org.). Magistério: construção cotidiana. Petrópolis: Vozes, 1997. p. 51-68.

DEWEY, J. Como pensamos: como se relaciona o pensamento reflexivo com o processo educativo, uma reexposição. 4. ed. São Paulo: Nacional, 1979.

ELLIOT, J. Recolocando a pesquisa-ação em seu lugar original e próprio. In: GERALDI, C. M. G.; et al. (Orgs.). Cartografias do trabalho docente. Campinas, SP: Mercado das Letras, 1998. p. 137-152.

ESCUDERO, J. M. Formación centrada en la escuela. Sevilla, Jornadas "El centro educativo: nuevas perspectivas organizativas", 1989.

FERRÉS, J. Vídeo e educação. Porto Alegre: Artes Médicas, 1996.

IMBERNÓN, F. Formação docente e profissional: formar-se para a mudança e a incerteza. 2. ed. São Paulo, Cortez, 2001.

LORENCINI JÚNIOR, Á. O professor e as perguntas na construção do discurso em sala de aula. 2000. Tese (Doutorado em Educação). Universidade de São Paulo, São Paulo.

PARANÁ (Estado). Secretaria da Educação. Resolução n. 10/2003. Dá nova redação à Resolução n. 06/2003, que trata da regulamentação de distribuição de aulas. Disponível em: 
$<$ http://www.diaadiaeducacao.com.br/portals/portal/institucional/def/pdf/def_ef_resol 1003.pdf>. Acesso em: 12 de maio/2005.

SADALlA, A. M. F. A. Com a palavra, a professora: suas crenças, suas ações. Campinas, SP: Editora Alínea, 1998.

SADALLA, A. M. F. A.; LAROCCA, P. Autoscopia: um procedimento de pesquisa e de formação. Educação e Pesquisa, São Paulo, vol. 30, n 3, set./dez. 2004, p. 419433. Disponível em: <http://www. scielo.br/scielo.pdf> Acesso em: 26 de março/2006.

SAINT-ONGE, M. $O$ ensino na escola: o que é, como se faz. 2. ed. São Paulo: Loyola, 2001.

SCHÖN, D. A. Educando o profissional reflexivo: um novo design para o ensino e a aprendizagem. Porto Alegre: Artes Médicas Sul, 2000.

SILVA, L. H. A; SCHNETZLER, R. P. Buscando o caminho do meio: a "sala de espelhos" na construção de parcerias entre professores e formadores de professores de ciências. Ciência \& Educação, Bauru: ABRAPEC, vol. 1, n. 6, p. 43 - 53, 2000. Disponível em:http://www.fc.unesp.br/pos/revista/pdf/revista6vol1/art5rev6vol1.pdf>. Acesso em: 14 de maio/2006.

ZEICHNER, K. M. El maestro como profesional reflexivo. Cuadernos de pedagogia, n. 220, 1992. p. 44-49.

ZEICHNER, K. M.; DINIZ-PEREIRA, J. E. Pesquisa dos educadores e formação docente voltada para a transformação social. Cadernos de Pesquisa, vol. 35, n. 125, p. 63-80, maio/ago. 2005.

DATA RECEBIMENTO: 15/06/2007

DATA APROVAÇÃO: 30/08/2007 